Carta ao editor

\section{Hb D/Talassemia beta associada à anemia crônica}

\author{
Paulo C. Naoum ${ }^{1}$ \\ Magaly S. Moraes ${ }^{1}$ \\ Janaina Radispiel ${ }^{1}$ \\ Priscila P. Cavalheri ${ }^{2}$ \\ Fábio F. Valeri ${ }^{2}$
}

1 - Academia de Ciência e Tecnologia de São José do Rio Preto, SP

2 - Instituto de Patologia e Citologia Prof. Dr.

Victório Valeri, Ribeirão Preto, SP

\section{Sr. Editor,}

A Hb D é uma hemoglobina variante com mutações em diferentes pontos da globina beta, fatos que determinam pelo menos quatro tipos distintos: $\mathrm{Hb} \mathrm{D}$ Iran ( $\beta 22$ Glu $\rightarrow$ Lis), Hb D Ibadan ( $\beta 97$ Tre $\rightarrow$ Lis), Hb D Beograd ( $\beta 121 \mathrm{Glu} \rightarrow$ Val) e Hb D Punjab ou Los Angeles $(\beta 121 \mathrm{Glu} \rightarrow \mathrm{Gln})$. O tipo mais comum entre os genótipos de $\mathrm{Hb}$ D é a Hb D Punjab ou Los Angeles que foi descrita em 1950 por Itano e Neel (1). No Brasil, em amplo estudo realizado em diversas regiões e avaliando 100 mil pessoas, observou-se que os casos de $\mathrm{Hb} \mathrm{D}$ identificados eram do tipo D Punjab ou Los Angeles, com prevalência média do genótipo da $\mathrm{Hb} \mathrm{AD}$ na proporção de um caso para cinco mil pessoas analisadas $(2,3)$. A Hb D migra na mesma posição da $\mathrm{Hb} \mathrm{S}$ em eletroforeses alcalinas, e a diferenciação entre as hemoglobinas $\mathrm{S}$ e $\mathrm{D}$ se faz por meio de eletroforese em agar-ácido $(3,4)$. A determinação específica dos tipos de $\mathrm{Hb} \mathrm{D}$ pode ser efetuada por eletroforeses de isofocalização e de cadeias polipeptídicas de globinas, PCR e HPLC (5).

A homozigose da $\mathrm{Hb} \mathrm{D}$, ou Hb DD, é uma situação rara, mesmo na região de Punjab (India) onde a prevalência do heterozigoto $(\mathrm{Hb} \mathrm{AD})$ é variável entre 2 e $3 \%(4,6)$. A $\mathrm{Hb} \mathrm{DD}$ - também conhecida por doença de $\mathrm{Hb} \mathrm{D}$ - se caracteriza por discreta anemia microcítica e hipocrômica, e a concentração da Hb D é próxima de 97 e 98\% (4).

A interação entre $\mathrm{Hb} \mathrm{D}$ e talassemia beta também é uma situação muito rara, com poucos casos relatados na literatura internacional e também apresenta discreto grau de anemia microcítica e hipocrômica $(4,5)$.

A presente comunicação se refere aos resultados do estudo familiar de um paciente do sexo masculino, com 37 anos de idade, que relata anemia desde a infância. Resultados de seus exames eletroforéticos anteriores realizados em outros centros referiam a anemia falciforme (Hb SS), contrapondo com as avaliações clínicas e hematológicas. Amostras de sangue do paciente foram encaminhadas ao Centro de Referência de Hemoglobinas da Academia de Ciência e Tecnologia, cujas análises mostraram anemia microcítica e hipocrômica de grau discreto, presença de anisocitose e poiquilocitose destacadas por micrócitos, esquisócitos, dacriócitos, pontilhados basófilos e policromasia. As dosagens de ferro sérico resultaram em $122 \mu \mathrm{g} / \mathrm{dl}(\mathrm{N}: 55$ - 150) e a capacidade de fixação do ferro foi de $248 \mu \mathrm{g} / \mathrm{dl}(\mathrm{N}: 250$ - 410). A análise eletroforética alcalina identificou uma fração anormal na posição de $\mathrm{Hb} \mathrm{S}$ com concentração de $82,4 \%$, além de $\mathrm{Hb}$ A $(4,2 \%)$, Hb Fetal $(8,1) \%$ e $\mathrm{Hb} \mathrm{A}_{2}(5,3 \%)$, entretanto a eletroforese em agar-ácido mostrou que a fração anormal se tratava de fato da $\mathrm{Hb} \mathrm{D}$. Para a correta determinação do genótipo do paciente foram solicitadas amostras de sangue dos pais e familiares para análises complementares. Essas

Tabela - Valores do eritrograma e fracionamento eletroforético de hemoglobinas na família do paciente com $\mathrm{Hb}$ D/beta talassemia.

\begin{tabular}{|l|c|c|c|c|}
\hline & Paciente & Pai & Mãe & Irmão \\
\hline $\mathrm{Gv}\left(\mathrm{X} 10^{6} / \mathrm{mm}^{3}\right.$ & 5,38 & 6,30 & 4,41 & 5,56 \\
\hline $\mathrm{Ht}(\%)$ & 34 & 40 & 40 & 38 \\
\hline $\mathrm{Hb} \mathrm{g} / \mathrm{dl}$ & 11,4 & 13,0 & 13,8 & 13,0 \\
\hline $\mathrm{VCM}\left(\mu^{3}\right)$ & 64 & 64 & 90 & 68 \\
\hline $\mathrm{HCM}(\mathrm{pg})$ & 21 & 21 & 31 & 23 \\
\hline $\mathrm{Hb} \mathrm{A}(\%)$ & 4,2 & 93,8 & 51,3 & 5,0 \\
\hline $\mathrm{Hb} \mathrm{A}(\%)$ & 5,3 & 6,2 & 2,0 & 4,6 \\
\hline $\mathrm{Hb} \mathrm{F}(\%)$ & 8,1 & zero & zero & 8,8 \\
\hline $\mathrm{Hb} \mathrm{D}(\%)$ & 82,4 & zero & 46,7 & 81,6 \\
\hline
\end{tabular}




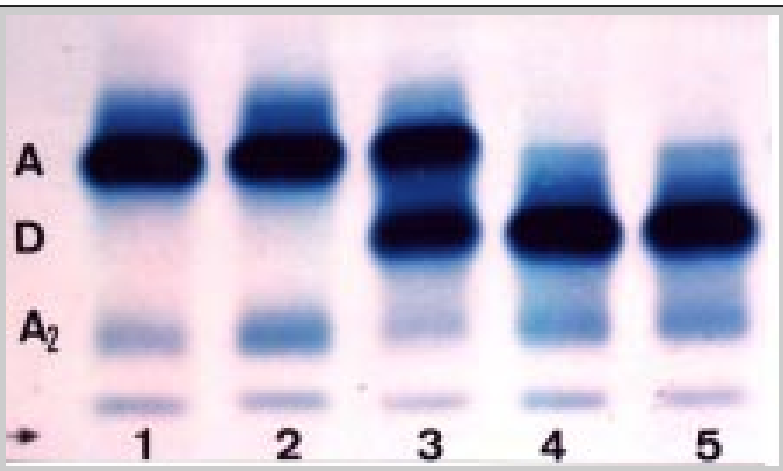

Eletroforese de hemoglobinas em agarose alcalina ( $\mathrm{pH}$ 8,6). 1:Hb AA (padrão), 2: $\mathrm{Hb} A A_{2} \uparrow$ (pai), 3: $H b A D$ (mãe), 4: Hb D/ßTal. (paciente), 5: Hb D/ßTal. (irmão).

análises indicaram a presença de talassemia beta heterozigota (ou menor) no pai, Hb AD na mãe, e genótipo similar no irmão (tabela e figura). Com base nesses resultados eletroforéticos e hematimétricos concluiu-se tratar de interação $\mathrm{Hb} \mathrm{D} /$ talassemia beta, presentes no paciente e em seu irmão. A qualificação do tipo da $\mathrm{Hb} \mathrm{D}$ foi efetuada por meio de eletroforese de isofocalização, bem como por eletroforese de cadeias polipeptídicas de globina que indicaram tratar-se de $\mathrm{Hb}$ D Punjab ou Los Angeles.

Diante do conjunto de resultados e das situações relatadas na presente comunicação, conclui-se que efetiva caracterização de genótipos de hemoglobinas variantes, notadamente aqueles com indicações clínicas de anemia, deva ser contemplada com análises eletroforéticas alcalinas, em agar-ácido e isofocalização, bem como dos valores hematimétricos e análises da morfologia eritrocitária, obtidos de análises de familiares, especialmente dos pais.

\section{Hb D/ Beta thalassaemia associated with chronic anaemia}

Paulo C. Naoum, Magali S. Moraes, Janaina Radispiel, Priscila P. Cavalheri, Fábio V. Valeri

\author{
Abstract \\ We describe a case of $\mathrm{Hb}$ D/Beta thalassemia \\ associated with chronic anemia. Hematological \\ analyses performed in a patient with chronic anemia \\ demonstrating microcytosis and hypochromic in his
}

erythrocytes. Specific laboratory diagnosis performed by alkaline and acid electrophoresis, and fetal determination by alkali resistance, indicated it to be $H b \mathrm{D}$ associated with beta thalassemia. Analyses carried out on his family (father, mother and brother) confirmed the suspected diagnosis. Hb D/Beta thalassemia is a very rare interaction in the Brazilian population, and its determination required specific laboratorial techniques and hematological analyses.

\section{Referências Bibliográficas}

1. Itano HA, Neel JV. A new inherited abnormality of human hemoglobin. Proc. Nat. Acad. Sc, 1950. 36: 613-617.

2. Naoum PC, Mattos LC, Cury PR. Prevalence and distribution of abnormal hemoglobins in state of São Paulo, Brazil. Bull. Pan Am. Health Organ., 1984. 18: 127-138.

3. Naoum PC. Hemoglobinopatias e talassemias. São Paulo, Sarvier, 1997, 168p.

4. Weatherall DJ, Clegg JB. Thalassaemia syndromes. Oxford, Blackwell Scientific Publications, 1981, 380-382p.

5. Steinberg MH, Forget BG, Higgs DR, Nagel RL. Disorders of Hemoglobin. Cambridge, Cambridge University Press, 2001, 1269p.

6. Lehmann H, Hunstman RG. Man's haemoglobins. Amsterdan. North-Holland Publishing Companhy, 1974, 478p.

Recebido : 08/11/01

Aceito : 09/02/02

Correspondência para: Paulo Cesar Naoum

Academia de Ciência e Tecnologia.

Rua Bonfá Natale, 1860. 15020-130.

São José do Rio Preto. SP

E-mail: a.c.t.@zaz.com.br 